$\$$ Research Square

Preprints are preliminary reports that have not undergone peer review.

They should not be considered conclusive, used to inform clinical practice,

or referenced by the media as validated information.

\title{
Students' "D"ILEMMA: An Assessment of Knowledge, Attitudes and Practice Toward Vitamin D Among University Students
}

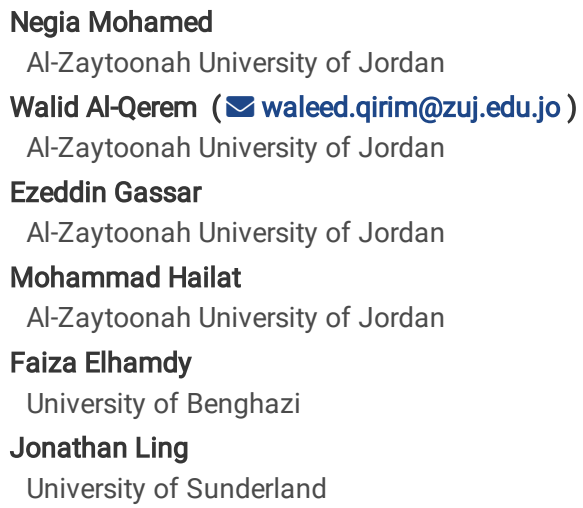

Research Article

Keywords: Vitamin D, Supplements, Knowledge, Attitude, Practice, Sun Exposure, Fortification, university students, Jordan

Posted Date: December 3rd, 2020

DOI: https://doi.org/10.21203/rs.3.rs-113664/v1

License: (c) (1) This work is licensed under a Creative Commons Attribution 4.0 International License. Read Full License 


\section{Abstract}

Background: The message delivered to the public regarding vitamin D is unclear, and contradictory; particularly regarding sun exposure; previous studies in Jordan have revealed high prevalence of low vitamin D among university students. The aim of this study was to investigate university students' knowledge, attitudes and practice regarding vitamin $\mathrm{D}$.

Method: A web-based cross-sectional survey completed by students at a Jordanian university in 2019. Binary logistic regression analysis was used to predict supplement use.

Results: 496 students completed the questionnaire. The mean knowledge score was $31.3( \pm 11.3)$ out of 100 . Women had significantly higher beliefs that vitamin $D$ deficiency is an escalating health issue $(p<0.01)$. Negative practices regarding sun exposure was significantly higher in women than men $(p<0.01)$. The majority of participants recognized that insufficient sun exposure was a cause of vitamin D deficiency, but $50.7 \%$ avoid sun exposure, and $67.6 \%$ expose only their face and hands. The consumption of fortified foods (OR 3.59-; $<0.001$ ) was the only studied variable associated with vitamin D consumption.

Conclusion: There is a gap between knowledge, attitude, and practice regarding vitamin $\mathrm{D}$ which can be bridged by promoting Vitamin $\mathrm{D}$ related awareness.

\section{Background}

Vitamin D deficiency is a widespread global condition(1). Vitamin D is naturally present in relatively few foods, therefore diet is considered a poor source of vitamin $D$ that accounts for only $10 \%$ of the intake of vitamin $D$; the rest is obtained by the exposure of unprotected skin to sunlight UVB radiation(1). Jordan is a sunny country having sunshine for an average of 10 hours per day during summer and 8 hours per day during winter(2). Therefore, exposure to UVB radiation should be sufficient for optimal vitamin D production(1). However, the rate of vitamin D deficiency in Jordan has an increasing trend in all ages and genders (3). The high prevalence of vitamin D deficiency in sunny countries has also been reported in several other studies $(4,5)$.

Vitamin D deficiency is often thought to be an exclusively elderly or hospitalized patient's problem. In contrast, many studies have found a higher prevalence of low vitamin D status among younger adults (6). Strikingly high prevalence of low vitamin D status has been found in Saudi Arabia(7) and Qatar (8) (100\% and $97.2 \%$ respectively) among university students. In Jordan the prevalence of vitamin D deficiency among female university students was lower (31.2\%) than Saudi Arabia and Qatar but still considered high (2).

University students are the potential future makers and they represent about $12 \%$ of the Jordanian population(9). In addition , early health attitudes and beliefs are difficult to change in later life (10).Furthermore, university students are reasonably healthy (11), which minimizes the bias related to the influence of illness on health behavior (12).

Consequently, a thorough understanding of students' knowledge and attitudes toward vitamin $\mathrm{D}$, the association between vitamin $\mathrm{D}$ and sun exposure and the consumption of vitamin D rich food or supplements, is essential before being able to create effective health promotion messaging and other intervention strategies. To date, no other studies have investigated the level of vitamin D knowledge, attitude and practice in Jordan. This study will assess knowledge, attitudes and practice of students regarding vitamin $D$, its association to sun exposure and the consumption of vitamin $D$ food or supplementations among Jordanian university students drawn from non-health-related faculties.

\section{Methods}

\section{Study design, sitting and participants}

A cross-sectional web-based survey was designed using the Google survey tool (Google Forms), and the generated link was embedded in an invitation sent to all registered students during summer semester at Al-Zaytoonah University of Jordan (ZUJ) via email . Only students registered in the summer semester were recruited to avoid any potential recall bias when asked about sun exposure, as it is most importantly during the summer.

The inclusion criteria for the study were current non-medical or para-medical students at ZUJ to avoid the influence of knowledge acquired during their study. The emails sent to the participants contained a personalized invitation that described the nature of the survey.

The Google form was set to allow only one submission per participant and completing all questions was mandatory before submission. Three reminder emails were sent to ensure a reasonable participation rate.

\section{Measures}

Due to the lack of a locally-validated questionnaire on knowledge, attitude, and practice regarding vitamin D, we developed a new questionnaire (see online repository). The survey questions were adapted after an extensive and thorough review of the previously published literature and modified to be applicable to the Jordanian population.

\section{Socio-demographic measures}

Socio-demographic information was collected including age, gender, marital status, average household income, and smoking habits. The Fitzpatrick skin type chart photo was included in the questionnaire to classify the participants' skin color (13). The color palate used in the chart photo was adapted from (D'Orazio et al., 2013)(14) and participants were asked to compare the color palate to their upper inner arm. 
Physical activity was assessed by asking the students how many times per week they exercise enough to work up a sweat. Students were classified as physically active if they exercise to a sweat three or more times per week. Exposure to the sun at home was classified into four categories: no exposure, sun exposure via window glass only, has an open area for sun exposure with lack of privacy, and place of residence has an open area for sun exposure with high privacy.

As there is no local validated questionnaire for assessment of dietary vitamin D intake, vitamin D containing food items were obtained from a short validated questionnaire(15) and the frequencies of intake were measured according to a Jordanian validated food frequency questionnaire(16). The final version of the questionnaire includes four food items: oily fish, butter, egg, and meat, in addition to low vitamin D sources including olive oil and unfortified milk.

\section{Knowledge, attitude, and practice}

To assess knowledge we developed a questionnaire consisting of 30 questions. Knowledge score was calculated according Boland et al.(17) (See Additional file 1). One point was added for each correct answer in questions that included one correct option, and for questions with multiple correct answers, one point was counted for each correct choice and one point was subtracted for each incorrect choice. The scores then were converted to percentages by dividing the scores by the highest possible score (30), then multiplied by 100. Regarding the question on the best time to be exposed to the sun to induce vitamin $D$ synthesis, participants were provided with 5 answers; any student who answered one or more correct answer without choosing any incorrect answer was categorized as knowledgeable about the best time to be exposed to the sun.. Additional questions that evaluated attitudes and practices about vitamin $\mathrm{D}$ and

sun exposure were included in the questionnaire. To assess the consumption of vitamin $D$ rich food, points were added based on the consumption frequencies (less than once weekly: 1 point, once weekly: 2 points, and more than once weekly: 3 points). Frequencies were transformed into percentages.

\section{Validation of the questionnaire}

The questionnaire content validity was evaluated by and expert panel composed of three experts. Formulated in English the questionnaire was translated to Arabic and back translated by different translator, then the two English version were compared. Face validity of the Arabic version was conducted by interviewing 30 students and the questionnaire was modified according to their feedback. The responses from the pilot testing were excluded from the final analysis.

\section{Statistical Analysis}

Descriptive statistics were used to describe the study findings. Categorical variables were presented as frequencies (percentages) whereas continuous variables were presented as means (standard deviations). The $\chi 2$ test was used to assess the associations between the sample characteristics and their vitamin D knowledge and practices and to evaluate the association between participants' knowledge and practices. Binary logistical regression was conducted to assess the contribution of different factors to the use of vitamin D supplements and the results of the regression were represented as odds ratios and 95\% Confident Interval (CI). P-values $<0.05$ were considered significant. IBM SPSS Statistics 25 was used to analyze the data and to create figures.

\section{Results}

The number of sent invitations was 2,150 (the number of eligible students who were registered in the summer semester). We received responses from 496. The response rate was $23 \%$ ), which is higher than the minimum acceptable response rate(18).

\section{Socio-demographic characteristics}

The socio-demographic characteristics of participants are shown in Table 1. Females made up 67.1\% of the participants . The mean age of the participants was $23.52 \pm 4.1$ years. The skin color of most of the participants ranged between Fitzpatrick skin type III (light brown) (41.1\%) and type IV (moderate brown) (43.1\%). Almost three-quarters of participants $(74.6 \%)$ of the participants were physically inactive.

The largest group of the participants (46\%) had access to an open area in their homes but without privacy, and only $2.8 \%$ reported that they had no kind of sun exposure in their home.

\section{Sources of information about vitamin D and attitude toward vitamin D}

As Table 2 shows, all participants had heard of vitamin $D$ and the majority of the participants $(78.8 \%)$ indicated that the primary source of information about vitamin D was from educational centers, followed by healthcare providers $(42.9 \%)$. Likewise, the preferred source of information for more than half of them (53\%) was educational centers followed by healthcare providers (38.5\%). Most (79.4\%) participants agreed that vitamin D deficiency is an escalating health issue in the region and all were interested in getting more knowledge about vitamin D. Nevertheless, $44.6 \%$ of participant were unconcerned about their vitamin $D$ levels.

\section{Knowledge and attitudes regarding vitamin $D$ health benefits and the causes of its deficiency}

Most participants knew that vitamin $D$ is essential for bone integrity and for prevention of osteoporosis, but none knew that there is a role of vitamin $D$ in prevention of osteomalacia (Table 2). Moreover, other essential benefits of vitamin D were less known; only a third (32.5\%) of participants knew that vitamin D is important for the integrity of muscles. The primary cause of vitamin D deficiency according to participants was insufficient sun exposure (82.3\%), followed by insufficient nutritional intake (39.7\%) and the least mentioned cause was obesity $(10.7 \%)$.

Knowledge and attitude regarding nutritional sources of vitamin and sun exposure 
As shown in Table 2, 52.8\% of participants acknowledged that the nutritional sources of vitamin D are insufficient and most of them (75.8\%) believed that the main source of vitamin D is the sun. Nevertheless, $75.6 \%$ did not know the best time to be exposed to the sun for cutaneous production of vitamin $D$ and $36.3 \%$ of the participants were aware of the association between dark skin color and vitamin D deficiency. Only $9.7 \%$ of the participants regarded oily fish as a source of vitamin D. The majority $78.6 \%$ ) of respondents believed that vitamin D consumption is important only when sun exposure is limited and $79.4 \%$ believed that vitamin $\mathrm{D}$ rich foods are costly.

Participants' knowledge scores are presented as percentages (Figure 1$)$. The mean ( \pm SD) was $31.3 \%( \pm 11.25)$ and only $7 \%$ of the participants got a score of $50 \%$ and above. The highest score was $66.67 \%$.

\section{Sun exposure practice}

As Table 3 shows $50.6 \%$ of the participants usually avoid exposure to the sun, and $57.9 \%$ routinely use sunscreen. From 10 am to 4 pm, $45.6 \%$ spend only less than 30 minutes outdoors during the weekdays and $62.3 \%$ of them spend less than 30 minutes outdoors during the weekends. Moreover, only $26.6 \%$ were exposed to the sun in the right time for vitamin D synthesis. The main sun-exposed body parts of the participants were face and hands (67.7\%), legs were exposed in $6.7 \%$ of the participants. Totally covered body with no parts exposed to the sun was practiced by (2.2\%) of the participants.

\section{Vitamin D containing food, fortified food and vitamin D supplement, consumption practice}

As indicated by the weekly frequency of vitamin D rich food consumption (Table 3), the least consumed food was oily fish, followed by butter, eggs. The most consumed was meat. A third of participants reported that they are taking vitamin D supplements. Regarding the consumption of vitamin D-fortified food, $34.5 \%$ of the participants reported consuming fortified food and $48.8 \%$ were unsure.

Figure 2 shows the consumption of vitamin D rich food percentages, the mean was $72.9 \%( \pm 14.7)$. Over $95 \%$ of participants got a score of $50 \%$ or more and the lowest reported percentage was $33.3 \%$.

\section{Association between sample characteristics and knowledge and practices related to vitamin D}

Table 4 shows that females significantly higher beliefs that vitamin D deficiency is an escalating health issue (84.7\%) than males. In addition, their negative practices regarding sun exposure was statistically significant compared to males, as they reported covering more of their bodies, exposing only face and hands ( $81.1 \%$ ) and spend less than 30 minutes during $10 \mathrm{am}-4 \mathrm{pm}$ time period of the day outside during weekends ( $64.6 \%)$. Significant differences between male and females, were found in use of sunscreen and avoidance of sun exposure habits - only (6.7\%) of males used sunscreen routinely compared to $82.9 \%$ of females, and $58 \%$ of females compared to $35.3 \%$ of males reported avoiding sun exposure.

Regarding the knowledge about the best time to be exposed to the sun for vitamin D synthesis (around the solar noon), $78.1 \%$ of females did not know the best time for vitamin D synthesis, which was reflected in their practice toward sun exposure as three-quarters of them (76\%) reported being exposed to the sun during the time of day when little vitamin D synthesis might occur.

\section{Association between vitamin D knowledge and beliefs with practices}

As shown in Table 5, the participants who knew the best time for sun exposure for vitamin D synthesis had significantly higher sun exposure at the right time when compared with those who did not know $(p<0.01)$. However, the beliefs of the sun as the best source of vitamin $D$, and insufficient sun exposure are the main cause of vitamin D deficiency did not have any significant effect on sun exposure time or duration of sun exposure during both weekdays and weekends. No significant association was found between the acknowledgment of a certain types of foods as a good source of vitamin $D$ and their consumption.

Table 6 shows the results of the logistical regression of the factors that can contribute to vitamin D supplement use. The only significant contribution was found for the consumption of fortified foods which increased the odds of consuming vitamin D supplements.

\section{Discussion}

Although Jordan is considered a sunny country[2], the prevalence of low vitamin D status is high in both genders, particularly among young adults of (18-39 years) compared to older age groups $(2,19)$.. This study aimed to evaluate the current knowledge, attitude, and practice towards vitamin $D$ among young, educated, adults.

\section{Knowledge score}

The mean of knowledge score of the participants in this study was $31.3 \%$, which is close to previously reported scores in China(20) and Canada(21) but significantly lower than that of undergraduate health science students in Saudi Arabia(22).

Overall, participants demonstrated that the term, "vitamin D" had been heard, which is higher than an Australian study in which more than one-third of the participants had not heard of vitamin $\mathrm{D}(23)$, although the latter group were not university students as in the current study.

\section{Vitamin D - knowledge attitude and practice, regarding information sources, food sources, health benefits, and causes of its deficiency}

Educational centers (schools and universities) were the most commonly reported and preferred source of information about vitamin D among the participants, followed by healthcare providers unlike other studies which found that healthcare providers(24) and the Internet(17) were the main knowledge sources for 
participants. Therefore, healthcare providers must develop their role, since they were the second most preferred source of information for the current study participants.

The essential role of vitamin D in bone integrity was the most recognized benefit, in line with a similar study conducted in the United Kingdom (17). The importance of vitamin $\mathrm{D}$ in maintaining normal calcium levels, and its role in muscle integrity were known by only half of participants. None of the participants knew of the role of vitamin $D$ in the prevention of osteomalacia, which is an early sign of vitamin D deficiency (25). However, this could be due to the lack of a clear diagnostic criteria of osteomalacia (25), or unfamiliarity of the term, that may lead to the ambiguity of the term among the general population. Furthermore, less than $10 \%$ of participants identified oily fish as a source of vitamin D and low percentages were also reported for other nutritional sources. This indicates that the main nutritional sources of vitamin $D$ and their essential role in health were not well-known by those surveyed, which suggests an unmet educational need regarding vitamin $D$ deficiency and its related factors.

The escalating problem of vitamin D deficiency in the region was perceived by more than two-thirds of participants, with females being significantly more aware of this issue, which is in line with previous a study(26). This emphasizes the need for better health education campaigns related to vitamin $D$ that targets both males and females, especially because a previous Jordanian study indicated that the prevalence of low vitamin D status among males was low $(54 \%)(3)$.

While nutritional insufficiency was reported by (40\%) of the participants as a possible cause of vitamin D deficiency, no significant associations were found between participants' consumption of different vitamin D rich foods and their beliefs. However, their reported consumption of vitamin D rich food was better than the reported rates in a Sudanese study(27) which might contribute to the lower prevalence of vitamin D deficiency among Jordanian women than Sudanese women(28).

\section{Knowledge, attitude and practice regarding the importance of sun exposure for vitamin $D$ synthesis}

High awareness of the relationship between insufficient sun exposure and vitamin D deficiency was observed among the participants. This was not observed in a Pakistani (29) study where only $36 \%$ of participants identified exposure to sunlight as a factor influencing vitamin D production. Nevertheless, consistent with a Chinese study(20), the high level of awareness in Jordanian participants did not improve their sun exposure practice. The relationship between attitude and practice of sun exposure reported among the participants is non-linear. This non-linear relationship could be better understood if the state of sun exposure at the participants' home is investigated.

Clearly, there is a barrier for sun exposure among the participants as most did not have a private area for sun exposure at home. This means that participants, especially females, may be less comfortable exposing their body to the sun due to Jordanian cultural barriers. Consequently, the lack of privacy for sun exposure compelled a quarter of the participants to practice sun exposure via glass windows only, which filters out the UVB radiation required for vitamin D synthesis(30).

Moreover, many of the females in our study did not report exposure to the sun during right time for vitamin D synthesis (31). In addition, compared to males, females during weekends had significantly lower duration (<30 min) of sun exposure during the period from 10 am to 4 pm, in which effective vitamin $D$ production could be achieved.

It is noteworthy to mention that the participants, who were well-informed about the right time for sun exposure for vitamin D synthesis, practiced significantly more sun exposure at that time than those who were unaware of this fact. Therefore, a more detailed message defining the correct time for sun exposure might enhance public sun exposure practice.

Furthermore, as reported in the present study, most of females in the conservative Jordanian society, cover most of their body parts sparing only their faces and hands, while the sun exposure of some of other body parts (eg back and legs)(1) is important for vitamin D synthesis. Similarly, males' exposure to sunlight did not differ much from the females' as $40.2 \%$ of the males exposed face/hands only.

Skin color has an important effect on the sun-induced synthesis of vitamin $D$, as the darker the skin, the less vitamin $D$ is synthesized by sun exposure (32). In our study, participants' knowledge of this information was poor, which implies that there is a need to clarify the importance of skin color for vitamin $D$ synthesis, especially among those with darker skin. Use of sunscreen was significantly higher in females than males, something also reported by an Indian study(33). Although in India this may be due to cultural factors related to skin colour with greater value placed on lighter skin tones(34). It is now generally accepted that sunscreen usage is not associated with vitamin D deficiency in real-life setting(35) and this was found in the current study, as four-fifths of the participants felt that sunscreen usage would not lead to vitamin D deficiency.

\section{Knowledge attitudes, and practice, toward vitamin D supplementation}

Despite the high prevalence of vitamin D deficiency and insufficiency among the Jordanian population(3), $60.5 \%$ of the participants did not consume vitamin D supplements, despite these being one of the main sources of vitamin D. The results of the logistical regression showed that the only studied factor that significantly contributed to the vitamin D supplements use was the consumption of vitamin D fortified food, unlike other studies, that reported knowledge scores had the greatest influence $(17,21)$.

It is worth reporting that milk was the second most consumed food among the participants, therefore milk fortification may help solve the vitamin $D$ deficiency problem in Jordan as one glass containing about four cubic centimeters of fortified milk will contain about 100 IU of vitamin D which counts for $1 / 6$ of the daily recommended intake (600 IU/day) of vitamin D for those between 1-70 years of age(36). 
Many factors that may predispose to vitamin D deficiency like skin color and cultural expectations of clothing are impossible or hard to modify. Therefore, more emphasis should be place on important alternative modifiable factors including use of vitamin D supplement and food fortification, which might improve the low vitamin D status.

\section{Strengths and limitations}

First, this study is the first that evaluate knowledge, attitude, and practice toward vitamin D, among university students and in Jordanian population in general. Second, the sample size is larger than similar studies $(17,37)$. Lastly, the study was conducted online, in a university with an infrastructure that allows free internet access for all students, where emails were sent to all of them, which eliminates coverage error, which led to a good response rate. However, there are several potential limitations of this study: first, the questionnaire based on self-reporting, which could lead to recall bias. Second, our results are limited in generalizability as the study population consisted mainly of Jordanian students .. This educated population are likely to have led to an underestimation of the knowledge related to vitamin D in the wider Jordanian population. Third, a selection bias may have occurred, as the participation in this study is voluntary, those who participated in the study might had more interest in it than those who did not participate. Nevertheless, since the researchers have no knowledge regarding the views and the characteristics of those who choose not to respond, the reason for non-response cannot be accurately predicted.

\section{Conclusion}

A gap between participants' knowledge, attitudes and practices regarding vitamin D was observed. This gap which could be bridged through health policy makers adopting food-based strategies, and design effective campaigns to raise awareness of vitamin $D$, the importance of safe exposure to the sun expressed in unit of time, the use of vitamin D supplements, food fortification and the regular inclusion of oily fish such as salmon in their diet to improve vitamin D status among the Jordanian population. Our results, might give a hint for the explanation of the high prevalence of low vitamin $D$ among younger adults in the sunny Jordan. While this conclusion may not be generalizable to the whole population as our sample were drawn from a single university, our study provides a baseline for further quantitative and qualitative studies regarding vitamin D knowledge, attitudes and practices within the wider population. Future studies could fruitfully explore this issue further by including vitamin D status as a proxy for vitamin D knowledge attitude and practice.

\section{Declarations}

Ethics approval and consent to participate

An informed consent form included in the online questionnaire was completed by the participants. Ethical approval was obtained from ZUJ ethical committee before the commencement of the study. All methods were carried out in accordance with Declaration of Helsinki.

Consent for publication

Not applicable

Availability of data and materials

The datasets generated and/or analyzed during the current study are available in the Zenodo repository. https://doi.org/10.5281/zenodo.4261766 (38)

Competing interests

The authors declare that they have no competing interests.

Funding

This research was funded by ZUJ (for publishing fees).

Authors' contributions

NM and WQ made a substantial contribution to the design of the work, acquisition, analysis, and interpretation of data. MH and FE have drafted the work and substantially revised it. EG made a substantial contribution to the conception, designing of the work, and drafting it. JL helped with the interpretation of the data and the drafting of the manuscript. All authors reviewed the manuscript.

Acknowledgements

We would like to thank Raghda Qarqaz for her contribution to the article writing and data analysis.

\section{References}

1. MF H. Sunlight, UV-radiation, vitamin D and skin cancer: how much sunlight do we need? Adv Exp Med Biol. 2020;1268:19-38.

2. Qatatsheh A, Tayyem R, Al-Shami I, Al-Holy MA, Al-Rethaia AS. Vitamin D deficiency among Jordanian university students and employees. Nutr Food Sci. 2015 Feb;45(1):68-82.

3. El-Khateeb M, Khader Y, Batieha A, Jaddou H, Hyassat D, Khawaja N, et al. Vitamin D deficiency and associated factors in Jordan. SAGE Open Med [-]. 2019 Jan 13 [cited 2020 Oct 1];7:205031211987615. Available from: http://journals.sagepub.com/doi/10.1177/2050312119876151

Page 6/16 
4. Nadeem S, Munim TF, Hussain HF, Hussain DF. Determinants of Vitamin D deficiency in asymptomatic healthy young medical students. Vol. 34, Pak J Med Sci. 2018. p. 1248-52.

5. IS D, HB N, HS A, MS M. Vitamin D Status among First Grade University Female Students. Bull Natl Nutr Inst Arab Repub Egypt. 2019;53(1):41-61.

6. Tønnesen R, Hovind PH, Jensen LT, Schwarz P. Determinants of Vitamin D status in young adults: Influence of lifestyle, sociodemographic and anthropometric factors. BMC Public Health. 2016;16(1).

7. Al-Elq A. The status of Vitamin D in medical students in the preclerkship years of a Saudi medical school. J Fam Community Med. 2012;19(2):100.

8. Rizk NM. The prevalence of vitamin D deficiency among female college students at Qatar University. Saudi Med J. 2011;32(9):964-5.

9. Department of statistics. Estimated Population of Jordan by Sex and Age Group, at End-year 2019 [Internet]. 2019. Available from: http://dosweb.dos.gov.jo/population/population-2/

10. Nelson MC, Story M, Larson NI, Neumark-Sztainer D, Lytle LA. Emerging adulthood and college-aged youth: An overlooked age for weight-related behavior change. Obesity. 2008;16(10):2205-11.

11. von Bothmer MIK, Fridlund B. Gender differences in health habits and in motivation for a healthy lifestyle among Swedish university students. Nurs Heal Sci. 2005;7(2):107-18.

12. Steptoe A, Wardle J. Health behaviour, risk awareness and emotional well-being in students from Eastern Europe and Western Europe. Soc Sci Med. 2001;53(12):1621-30.

13. Fitzpatrick TB. Soleil et Peau. Med Esthet. 1975;2:33-4.

14. D’Orazio J, Jarrett S, Amaro-Ortiz A, Scott T. UV radiation and the skin. Vol. 14, Int J Mol Sci. MDPI AG; 2013. p. $12222-48$.

15. Hedlund L. A Short Questionnaire for Assessment of Dietary Vitamin D Intake. Eur J Nutr Food Saf. 2014 Jan 10;4(2):150-6.

16. Tayyem RF, Abu-Mweis SS, Bawadi HA, Agraib L, Bani-Hani K. Validation of a food frequency questionnaire to assess macronutrient and micronutrient intake among jordanians. J Acad Nutr Diet. 2014;114(7):1046-52.

17. O'connor C, Glatt D, White L, Iniesta RR, O'connor C, Glatt D, et al. Knowledge, attitudes and perceptions towards vitamin d in a uk adult population: A cross-sectional study. Int J Environ Res Public Health [-]. 2018 Nov 1 [cited 2020 Oct 1];15(11). Available from: /pmc/articles/PMC6267199/? report=abstract

18. Ramshaw A. The Complete Guide to Acceptable Survey Response Rates [Internet]. [cited 2020 Oct 27]. Available from: https://www.genroe.com/blog/acceptable-survey-response-rate-2/11504?utm_campaign=NPS\&utm_medium=email\&_hsmi=93419731\&_hsenc=p2ANqtz9V62GBXJ5ev3PbCTzUrsv7MRGUTulm-EnFRwemk1w36ldUP-

Z3t1iAVnTTEvl8mnesSm9MY0LuVYud1wSACVHnWmda6Q\&utm_content=93419731\&utm_sourc

19. Batieha A, Khader Y, Jaddou H, Hyassat D, Batieha Z, Khateeb M, et al. Vitamin D status in Jordan: Dress style and gender discrepancies. Ann Nutr Metab. 2011 Apr;58(1):10-8.

20. Kung AWC, Lee K. Knowledge of vitamin D and perceptions and attitudes toward sunlight among Chinese middle-aged and elderly women: a population survey in Hong Kong. BMC Public Health. 2006;7:1-7.

21. Boland S, Irwin JD, Johnson AM. A Survey of University Students' Vitamin D-related knowledge. J Nutr Educ Behav [-]. 2015;47(1):99-103. Available from: http://dx.doi.org/10.1016/j.jneb.2014.08.013

22. Geddawy A, Al-burayk AK, Almhaine AA, Al-ayed YS, Bin-hotan AS. Response regarding the importance of vitamin D and calcium among undergraduate health sciences students in Al Kharj, Saudi Arabia. 2020;

23. Vu LH, Van Der Pols JC, Whiteman DC, Kimlin MG, Neale RE. Knowledge and attitudes about vitamin D and impact on sun protection practices among urban office workers in Brisbane, Australia. Cancer Epidemiol Biomarkers Prev. 2010;19(7):1784-9.

24. Kotta S, Gadhvi D, Jakeways N, Saeed M, Sohanpal R, Hull S, et al. Test me and treat me - Attitudes to vitamin D deficiency and supplementation: A qualitative study. BMJ Open [-]. 2015 Jul 14 [cited 2020 Oct 1];5(7):1-9. Available from: https://bmjopen.bmj.com/lookup/doi/10.1136/bmjopen-2014007401

25. Uday S, Högler W. Spot the silent sufferers: A call for clinical diagnostic criteria for solar and nutritional osteomalacia. J Steroid Biochem Mol Biol. 2019;188(January):141-6.

26. Arora H, Dixit V, Srivastava N. Evaluation of knowledge, practices of vitamin d and attitude toward sunlight among Indian students. Asian J Pharm Clin Res [-]. 2016 Jan [cited 2020 Nov 19];9(1):308-13. Available from:

https://www.researchgate.net/publication/290490087_Evaluation_of_knowledge_practices_of_vitamin_d_and_attitude_toward_sunlight_among_Indian_st

27. Ali S, Salih L, Saeed E. Awareness of medical students about vitamin D deficiency at Ahfad University for women, Sudan. Sudan J Paediatr. 2019;19(2):117-25.

28. Husain N, Badie Suliman A, Abdelrahman I, Bedri S, Musa R, Osman H, et al. Vitamin D level and its determinants among Sudanese Women: Does it matter in a sunshine African Country? J Fam Med Prim Care [-]. 2019 [cited 2020 Oct 3];8(7):2389. Available from: /pmc/articles/PMC6691462/? report=abstract

29. Tariq A, Khan SR, Basharat A. Assessment of knowledge, attitudes and practice towards Vitamin D among university students in Pakistan. BMC Public Health [-]. 2020 Mar 18 [cited 2020 Nov 12];20(1):1-10. Available from: https://link.springer.com/articles/10.1186/s12889-020-8453-y

30. Bernerd, F.; Moyal, D.; Pai, S.B.; Srinivas CR. Ultraviolet-induced skin damage and its prevention with sunscreen. In Basic Science for Modern Cosmetic Dermatology. Srinivas, C.R., Verschoore, M. E, editor. Jaypee Brothers Medical Publishers: New Dehli, India; 2014. 91 p.

31. Webb AR, Kazantzidis A, Kift RC, Farrar MD, Wilkinson J, Rhodes LE. Meeting vitamin D requirements in white caucasians at UK latitudes: Providing a choice. Nutrients. 2018;10(4):1-13.

Page $7 / 16$ 
32. Mohammad A, Alwadei A, Saad N, Al-Johani M, Saleh S, Alzamanan M, et al. Public Awareness of Vitamin " D " Deficiency among Children in Najran City and The Role of Primary Health Care Centers in Raising Their Awareness. Egypt J Hosp Med. 2018;70(12).

33. (PDF) Evaluation of knowledge, practices of vitamin d and attitude toward sunlight among Indian students [Internet]. [cited 2020 Oct 1]. Available from: https://www.researchgate.net/publication/290490087_Evaluation_of_knowledge_practices_of_vitamin_d_and_attitude_toward_sunlight_among_Indian_st

34. Kavita Karan. Obsessions with Fair Skin: Color Discourses in Indian Advertising. Advert Soc Rev [-]. 2008 [cited 2020 Nov 22];9(2). Available from: https://muse.jhu.edu/article/241033

35. Neale RE, Khan SR, Lucas RM, Waterhouse M, Whiteman DC, Olsen CM. The effect of sunscreen on vitamin D: a review [Internet]. Vol. 181, Br J Dermatol. 2019 [cited 2020 Oct 1]. p. 907-15. Available from: https://pubmed.ncbi.nlm.nih.gov/30945275/

36. Vitamin D - Health Professional Fact Sheet [Internet]. [cited 2020 Oct 4]. Available from: https://ods.od.nih.gov/factsheets/VitaminDHealthProfessional/\#h3

37. Aljefree N, Lee P, Ahmed F. Exploring Knowledge and Attitudes about Vitamin D among Adults in Saudi Arabia: A Qualitative Study. Healthcare [-]. 2017 Oct 16 [cited 2020 Oct 6];5(4):76. Available from: http://www.mdpi.com/2227-9032/5/4/76

38. Mohamed N, Al-Qerem W, Gassar E, Hailat M, A.M.Elhamdy F, Ling J. Students' "D"ILEMMA: An assessment of knowledge, attitudes and practice toward Vitamin D among university students. 2020 Nov 8 [cited 2020 Nov 12]; Available from: https://doi.org/10.5281/zenodo.4261766\#.X61Ho-XieLE.mendeley

\section{Tables}

Table 1 Study Sample Demographics

\begin{tabular}{|c|c|c|}
\hline Variable & \multicolumn{2}{|c|}{$\begin{array}{l}\text { Mean (SD) or Frequency (\%) } \\
\qquad(n=496)\end{array}$} \\
\hline Age & & $23.52(4.10)$ \\
\hline Body Mass Index (BMI) & & $24.43(5.65)$ \\
\hline \multirow[t]{2}{*}{ Sex } & Female & $333(67.1)$ \\
\hline & Male & 163(32.9) \\
\hline \multirow[t]{2}{*}{ Do you have any chronic illness? } & Yes & $27(5.4)$ \\
\hline & No & $469(94.6)$ \\
\hline \multirow[t]{3}{*}{ Smoking status } & Smoker & $74(14.9)$ \\
\hline & Non smoker & $404(81.5)$ \\
\hline & Ex-smoker & 18(3.6) \\
\hline \multirow[t]{2}{*}{ Marital status } & Single & $441(88.9)$ \\
\hline & Married & $55(11.1)$ \\
\hline \multirow[t]{3}{*}{ Average income (Jordanian dinars/month) } & Low income $(<600)$ & $109(32.5)$ \\
\hline & Moderate income(600-1000) & $123(36.7)$ \\
\hline & High income(>1000) & 103(30.7) \\
\hline \multirow[t]{4}{*}{ Skin color } & White skin & $16(3.2)$ \\
\hline & Light brown skin & $204(41.1)$ \\
\hline & Moderate brown skin & $214(43.1)$ \\
\hline & Dark brown skin & $62(12.5)$ \\
\hline \multirow[t]{2}{*}{ Physical activity } & Physically active & $125(25.4)$ \\
\hline & Physically inactive & $367(74.6)$ \\
\hline \multirow[t]{4}{*}{ Home exposure to the sun } & No exposure to the sun inside the residence & $14(2.8)$ \\
\hline & Sun exposure via glass only & $134(27)$ \\
\hline & Open area sun exposure with lack of privacy & $228(46.0)$ \\
\hline & Open area sun exposure with high privacy & $120(24.2)$ \\
\hline
\end{tabular}

Table 2 Knowledge and Attitude about Vitamin D 


\begin{tabular}{|c|c|c|}
\hline \multirow{2}{*}{$\begin{array}{l}\text { Variable } \\
\text { Information sources about vitamin D }\end{array}$} & \multicolumn{2}{|c|}{ Frequency $(\%)$} \\
\hline & Educational center school or university & $391(78.8)$ \\
\hline & Healthcare providers & 213(42.9) \\
\hline & Media & $129(26.0)$ \\
\hline & Websites and Facebook & 155(31.1) \\
\hline & Parents, relatives, or friends & 162(32.7) \\
\hline & Other sources & $11(2.2)$ \\
\hline \multirow[t]{2}{*}{ Knowledge about best time to expose to sun } & Knowledgeable* & $121(24.4)$ \\
\hline & Not knowledgeable** & $375(75.6)$ \\
\hline \multirow[t]{8}{*}{ Benefits of vitamin D } & Essential for the bone integrity & 405(81.7) \\
\hline & Prevention of osteoporosis & $355(71.6)$ \\
\hline & Prevention of rickets & 272(54.8) \\
\hline & Prevention of osteomalacia & $0(0)$ \\
\hline & Essential for muscle integrity & $161(32.5)$ \\
\hline & Protect against chronic diseases & 192(38.7) \\
\hline & Protect against weakness and fatigue & 261(52.6) \\
\hline & Unsure & $24(4.8)$ \\
\hline Familiarity with vitamin D & Familiar & $496(100)$ \\
\hline Interest in getting more knowledge about vitamin D & Interested & 496(100) \\
\hline \multirow[t]{4}{*}{ Preferred source of information about vitamin D } & Healthcare providers & 191(38.5) \\
\hline & Educational center school or university & 263(53.0) \\
\hline & Media and Internet & $32(6.5)$ \\
\hline & Parents, relatives, or friends & $9(1.8)$ \\
\hline \multirow[t]{14}{*}{ Causes of vitamin D deficiency } & Insufficient sun exposure & $408(82.3)$ \\
\hline & Nutritional insufficiency & 197(39.7) \\
\hline & Dressing style & 140(28.2) \\
\hline & Aging & $128(25.8)$ \\
\hline & Pregnancy & $61(12.3)$ \\
\hline & Obesity & $53(10.7)$ \\
\hline & Sunscreen usage & 100(20.2) \\
\hline & Genetic variability & $121(24.4)$ \\
\hline & Gender differences & 61(12.3) \\
\hline & Physical inactivity & $140(28.2)$ \\
\hline & Soft drinks & 64(12.9) \\
\hline & Smoking & $72(14.5)$ \\
\hline & Extra water drinking & $13(2.6)$ \\
\hline & Unsure & $11(2.2)$ \\
\hline Sources of vitamin D & Sun & $376(75.8)$ \\
\hline
\end{tabular}

Page 9/16 


\begin{tabular}{|c|c|c|}
\hline \multicolumn{2}{|c|}{$\begin{array}{ll}\text { Oily fish }\end{array}$} & \multirow{2}{*}{$\begin{array}{l}48(9.7) \\
13(2.6)\end{array}$} \\
\hline & Meat & \\
\hline & Dairy products & $23(4.6)$ \\
\hline & Eggs & $14(2.8)$ \\
\hline & Fortified cereal & $3(0.60)$ \\
\hline & Olive oil & $3(0.60)$ \\
\hline & Mushroom & $2(0.40)$ \\
\hline & Vegetables & $5(1.0)$ \\
\hline & Unsure & $10(2.0)$ \\
\hline \multirow[t]{2}{*}{ Is flour in Jordan fortified? } & Yes & $403(81.3)$ \\
\hline & No & $93(18.8)$ \\
\hline \multirow[t]{2}{*}{ Concerns about vitamin D levels } & Concerned & $275(55.4)$ \\
\hline & Not concerned & $221(44.6)$ \\
\hline \multirow[t]{3}{*}{ Vitamin $D$ deficiency is an escalating health issue in the region } & Yes & $394(79.4)$ \\
\hline & Unsure & $76(15.3)$ \\
\hline & No & $26(5.2)$ \\
\hline \multicolumn{3}{|l|}{ Do you agree with these sentences (Frequency (\%) of agree) } \\
\hline Nutritional sources of vitamin $\mathrm{D}$ are adequate & & 234(47.2) \\
\hline Vitamin D is important to maintain normal calcium levels & & 254(51.2) \\
\hline \multicolumn{2}{|l|}{ Vitamin D consumption is important only when sun exposure is limited } & $390(78.6)$ \\
\hline \multicolumn{2}{|l|}{ Dark-skinned people are more prone to vitamin D deficiency } & $180(36.3)$ \\
\hline \multicolumn{2}{|l|}{ Vitamin D rich foods are costly } & $394(79.4)$ \\
\hline
\end{tabular}

*Knowledgeable: if the student chose one or more correct answers without choosing any incorrect, ** Not knowledgeable: if the student chose any incorrect answer

Table 3 Sun exposure and vitamin D consumption practices 


\begin{tabular}{|c|c|c|}
\hline Variable & & Frequency $(\%)$ \\
\hline \multirow[t]{3}{*}{ Time spent outdoors during weekdays (10 am to $4 \mathrm{pm}$ ) } & Less than $30 \mathrm{~min}$ & $226(45.6)$ \\
\hline & $30-60 \mathrm{~min}$ & $120(24.2)$ \\
\hline & $>60 \mathrm{~min}$ & $150(30.2)$ \\
\hline \multirow[t]{3}{*}{ Time spent outdoors during weekends ( 10 am to $4 \mathrm{pm}$ ) } & Less than $30 \mathrm{~min}$ & $309(62.3)$ \\
\hline & $30-60 \mathrm{~min}$ & $70(14.1)$ \\
\hline & $>60 \mathrm{~min}$ & $117(23.6)$ \\
\hline \multirow[t]{2}{*}{ Sunscreen usage } & Use & $287(57.9)$ \\
\hline & Do not use & $210(42.1)$ \\
\hline \multirow[t]{5}{*}{ Sun-exposed body parts } & Face/hands/arms/legs & $33(6.7)$ \\
\hline & Face/hands/arms & $92(18.5)$ \\
\hline & Face/hands & $336(67.7)$ \\
\hline & Face & $24(4.8)$ \\
\hline & No parts are exposed to sun & $11(2.2)$ \\
\hline \multirow[t]{2}{*}{ Avoidance of sun } & Avoid usually & $251(50.6)$ \\
\hline & Do not avoid usually & $245(49.4)$ \\
\hline \multirow[t]{2}{*}{ Participant exposure to the sun } & At the right time* & $132(26.6)$ \\
\hline & Not at the right time & $364(73.4)$ \\
\hline \multirow[t]{3}{*}{ Consumption of vitamin D fortified foods } & Consume & $171(34.5)$ \\
\hline & Not sure & $242(48.8)$ \\
\hline & Do not consume & $83(16.7)$ \\
\hline \multirow[t]{3}{*}{ Consumption of milk } & Less than once weekly & $171(34.5)$ \\
\hline & Once weekly & $96(19.4)$ \\
\hline & More than once weekly & $229(46.2)$ \\
\hline \multirow[t]{3}{*}{ Consumption of butter } & Less than once weekly & $286(57.7)$ \\
\hline & Once weekly & $59(11.9)$ \\
\hline & More than once weekly & $151(30.4)$ \\
\hline \multirow[t]{3}{*}{ Consumption of eggs } & Less than once weekly & $70(14.10)$ \\
\hline & Once weekly & $101(20.4)$ \\
\hline & More than once weekly & $325(65.5)$ \\
\hline \multirow[t]{3}{*}{ Consumption of oily fish } & Less than once weekly & $155(31.3)$ \\
\hline & Once weekly & $213(42.9)$ \\
\hline & More than once weekly & $128(25.8)$ \\
\hline \multirow[t]{3}{*}{ Consumption of meat } & Less than once weekly & $67(13.5)$ \\
\hline & Once weekly & $82(16.5)$ \\
\hline & More than once weekly & $347(70.0)$ \\
\hline \multirow[t]{2}{*}{ Use of vitamin D supplements } & Use & 196(39.5) \\
\hline & Do not use & $300(60.5)$ \\
\hline
\end{tabular}

* Right time: around the solar noon; before noon, noon, and early after noon

Table 4 Association between sample characteristics and knowledge and practices related to vitamin D 


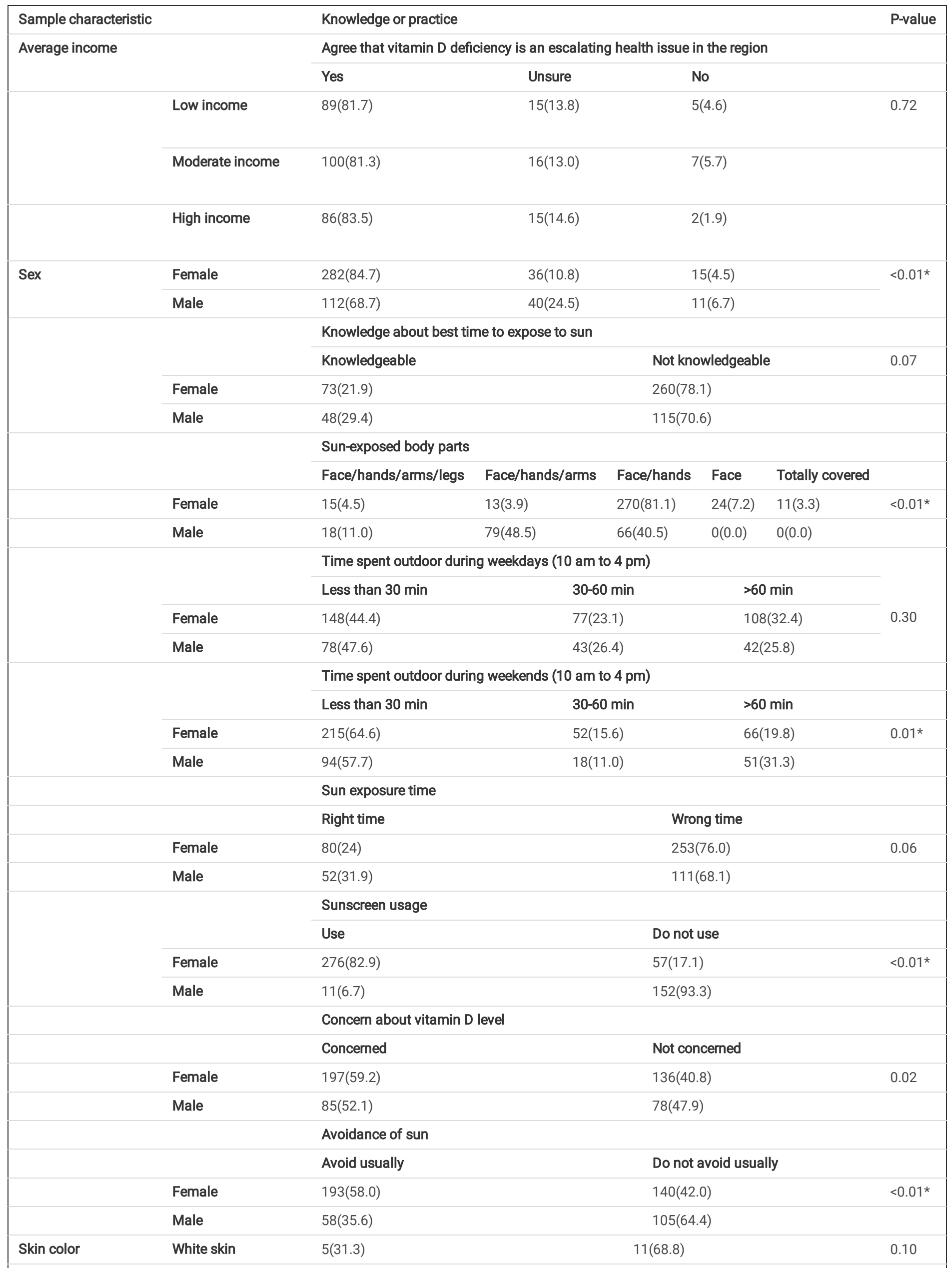

Page 12/16 


\begin{tabular}{|lll|}
\hline Light brown skin & $112(54.9)$ & 92(45.1) \\
\hline Moderate brown skin & $99(46.3)$ & 27(43.5) \\
\hline Dark brown skin & $35(56.5)$ & Agree that dark skinned are more prone to vitamin D deficiency than fair skinned \\
\hline & Yes & No \\
\hline White skin & $6(37.5)$ & $10(62.5)$ \\
\hline Light brown skin & $63(30.9)$ & $141(69.1)$ \\
\hline Moderate brown skin & $82(38.3)$ & $132(61.7)$ \\
\hline Dark brown skin & $29(46.8)$ & $33(53.2)$ \\
\hline
\end{tabular}

*Significant differences ( $p$-value<0.05)

Table 5 Association between vitamin $\mathrm{D}$ knowledge and beliefs with practices 


\begin{tabular}{|c|c|c|c|c|c|c|}
\hline & Knowledge & \multicolumn{4}{|l|}{ Practice } & $\begin{array}{l}\text { P- } \\
\text { value }\end{array}$ \\
\hline \multirow[t]{3}{*}{ Knowledge about best time to expose to sun } & & \multicolumn{2}{|c|}{ Exposed at the right time } & \multicolumn{2}{|c|}{ Exposed at the wrong time } & $<0.01 *$ \\
\hline & Knowledgeable & $57(47.1)$ & \multicolumn{3}{|c|}{$64(52.9)$} & \\
\hline & $\begin{array}{l}\text { Not } \\
\text { knowledgeable }\end{array}$ & $75(20.0)$ & \multicolumn{3}{|c|}{$300(80.0)$} & \\
\hline \multirow[t]{2}{*}{ Sun is the best source of Vitamin D } & Yes & 104(27.7) & \multicolumn{3}{|c|}{ 272(72.3) } & 0.35 \\
\hline & No & 28(23.3) & \multicolumn{3}{|c|}{$92(76.7)$} & \\
\hline \multirow{2}{*}{$\begin{array}{l}\text { Insufficient sun exposure is the main cause of vitamin D } \\
\text { deficiency }\end{array}$} & Yes & 109(26.7) & \multicolumn{3}{|c|}{ 299(73.3) } & 1.00 \\
\hline & No & $23(26.1)$ & \multicolumn{3}{|c|}{$65(73.9)$} & \\
\hline \multirow{4}{*}{ Sun is the best source of Vitamin D } & & \multicolumn{5}{|c|}{ Time spent outdoor during weekdays (10 am to $4 \mathrm{pm}$ ) } \\
\hline & & $<30 \mathrm{~min}$ & & $-60 \mathrm{~min}$ & $>60 \mathrm{~min}$ & \\
\hline & Yes & 165(43.9) & & $(24.5)$ & 119(31.6) & 0.36 \\
\hline & No & $61(50.8)$ & & $(23.3)$ & $31(25.8)$ & \\
\hline \multirow{2}{*}{$\begin{array}{l}\text { Insufficient sun exposure is the main cause of vitamin D } \\
\text { deficiency }\end{array}$} & Yes & $182(44.6)$ & & $2(25.0)$ & $124(30.4)$ & 0.58 \\
\hline & No & $44(50.0)$ & & $(20.5)$ & $26(29.5)$ & \\
\hline \multirow[t]{4}{*}{ Sun is the best source of Vitamin D } & & \multicolumn{5}{|c|}{ Time spent outdoor during weekends ( 10 am to $4 \mathrm{pm}$ ) } \\
\hline & & $<30 \mathrm{~min}$ & & $-60 \mathrm{~min}$ & $>60 \mathrm{~min}$ & \\
\hline & Yes & $225(59.8)$ & & $(15.7)$ & $92(24.5)$ & 0.09 \\
\hline & No & $84(70.0)$ & & $(9.2)$ & $25(20.8)$ & \\
\hline \multirow{2}{*}{$\begin{array}{l}\text { Insufficient sun exposure is the main cause of vitamin D } \\
\text { deficiency }\end{array}$} & Yes & $252(61.8)$ & & $(14.5)$ & $97(23.8)$ & 0.81 \\
\hline & No & $57(64.8)$ & & $(12.5)$ & $20(22.7)$ & \\
\hline \multirow[t]{3}{*}{ Sunscreen may cause vitamin $D$ deficiency } & & Use sunscreen & \multicolumn{3}{|c|}{ Don't use sunscreen } & \\
\hline & Yes & $57(57.0)$ & \multicolumn{3}{|c|}{$43(43.0)$} & 0.85 \\
\hline & No & $230(58.1)$ & \multicolumn{3}{|c|}{ 166(41.9) } & \\
\hline \multirow[t]{4}{*}{ Oily fish is one of the best sources of Vitamin D } & & \multicolumn{4}{|c|}{ Consumption of oily fish } & \\
\hline & & $\begin{array}{l}\text { Less than once } \\
\text { weekly }\end{array}$ & & $\begin{array}{l}\text { ce } \\
\text { ekly }\end{array}$ & $\begin{array}{l}\text { More than once } \\
\text { weekly }\end{array}$ & \\
\hline & Yes & 19(39.6) & & $(41.7)$ & $9(18.8)$ & 0.33 \\
\hline & No & $136(30.4)$ & & $3(43.1)$ & $119(26.5)$ & \\
\hline \multirow[t]{4}{*}{ Egg is one of the best sources of Vitamin D } & & \multicolumn{4}{|c|}{ Consumption of eggs } & \\
\hline & & $\begin{array}{l}\text { Less than once } \\
\text { weekly }\end{array}$ & & $\begin{array}{l}\text { ce } \\
\text { ekly }\end{array}$ & $\begin{array}{l}\text { More than once } \\
\text { weekly }\end{array}$ & \\
\hline & Yes & $2(14.3)$ & & 4.3) & $10(71.4)$ & 0.84 \\
\hline & No & $68(14.1)$ & & $(20.5)$ & $316(65.4)$ & \\
\hline \multirow[t]{4}{*}{ Meat is one of the best sources of Vitamin D } & & \multicolumn{4}{|c|}{ Consumption of meat } & \\
\hline & & $\begin{array}{l}\text { Less than once } \\
\text { weekly }\end{array}$ & & $\begin{array}{l}\text { ce } \\
\text { ekly }\end{array}$ & $\begin{array}{l}\text { More than once } \\
\text { weekly }\end{array}$ & \\
\hline & Yes & $2(15.4)$ & & .0) & 11(84.6) & 0.26 \\
\hline & No & $65(13.5)$ & & $(17.0)$ & $336(69.6)$ & \\
\hline
\end{tabular}

*Significant difference $(p-v a l u e<0.01)$

Table 6 Factors contributing to vitamin D supplementation use. A logistic regression predicting likelihood of supplement use on relevant factors $(\mathrm{n}=496)$ 


\begin{tabular}{|c|c|c|c|c|c|c|c|c|c|}
\hline & \multirow[t]{2}{*}{ B } & \multirow[t]{2}{*}{ S.E. } & \multirow[t]{2}{*}{ Wald } & \multirow[t]{2}{*}{ df } & \multirow[t]{2}{*}{$P$} & \multirow[t]{2}{*}{$\begin{array}{l}\text { Odds- } \\
\text { Ratio }\end{array}$} & \multicolumn{3}{|c|}{$\begin{array}{l}95 \% \mathrm{Cl} \text { of Odds- } \\
\text { Ratio }\end{array}$} \\
\hline & & & & & & & & Lower & Upper \\
\hline Sex (Females compared to males) & 0.37 & 0.39 & 0.91 & 1.00 & 0.34 & 1.45 & .68 & & 3.11 \\
\hline $\begin{array}{l}\text { Household average monthly income (Moderate income group } \\
\text { compared to low income group) }\end{array}$ & 0.36 & 0.29 & 1.57 & 1.00 & 0.21 & 1.44 & .81 & & 2.53 \\
\hline $\begin{array}{l}\text { Household average monthly income (High income group compared to } \\
\text { low income) }\end{array}$ & 0.16 & 0.30 & 0.27 & 1.00 & 0.60 & 1.17 & 0.65 & & 2.12 \\
\hline $\begin{array}{l}\text { Concerns about vitamin D deficiency ("Not Concerned" compared to } \\
\text { "Concerned") }\end{array}$ & -0.30 & 0.24 & 1.52 & 1.00 & 0.22 & 0.74 & 0.46 & & 1.19 \\
\hline Taking vitamin D fortified food ("Not sure" compared "Do not take") & 0.72 & 0.36 & 4.12 & 1.00 & $0.04 *$ & 2.06 & 1.03 & & 4.13 \\
\hline Taking vitamin D fortified food ("Take" compared to "Do not take") & 1.28 & 0.36 & 12.55 & 1.00 & $<0.01^{*}$ & 3.59 & 1.77 & & 7.28 \\
\hline Physical activity ("Inactive" compared to "Active") & -0.45 & 0.27 & 2.88 & 1.00 & 0.09 & 0.64 & 0.38 & & 1.07 \\
\hline Sunscreen usage ("Do not use" compared to "Use") & 0.23 & 0.35 & 0.42 & 1.00 & 0.52 & 1.26 & 0.63 & & 2.50 \\
\hline Avoidance of sun habits ("Avoid" compared to "Do not avoid") & -0.24 & 0.24 & 0.94 & 1.00 & 0.33 & 0.79 & 0.49 & & 1.27 \\
\hline Knowledge scores about vitamin D & -0.01 & 0.01 & 1.42 & 1.00 & 0.23 & 0.99 & 0.97 & & 1.01 \\
\hline Scores of consumption of vitamin D rich food & 0.03 & 0.07 & 0.20 & 1.00 & 0.65 & 1.03 & 0.90 & & 1.19 \\
\hline
\end{tabular}

Abbreviations: B coefficient (B), Standard Error (SE), Wald chi-square test (Wald), degrees of freedom (df), p-value (p), Confidence Interval (Cl). * Significance taken at $\mathrm{p}<0.05$.

\section{Figures}

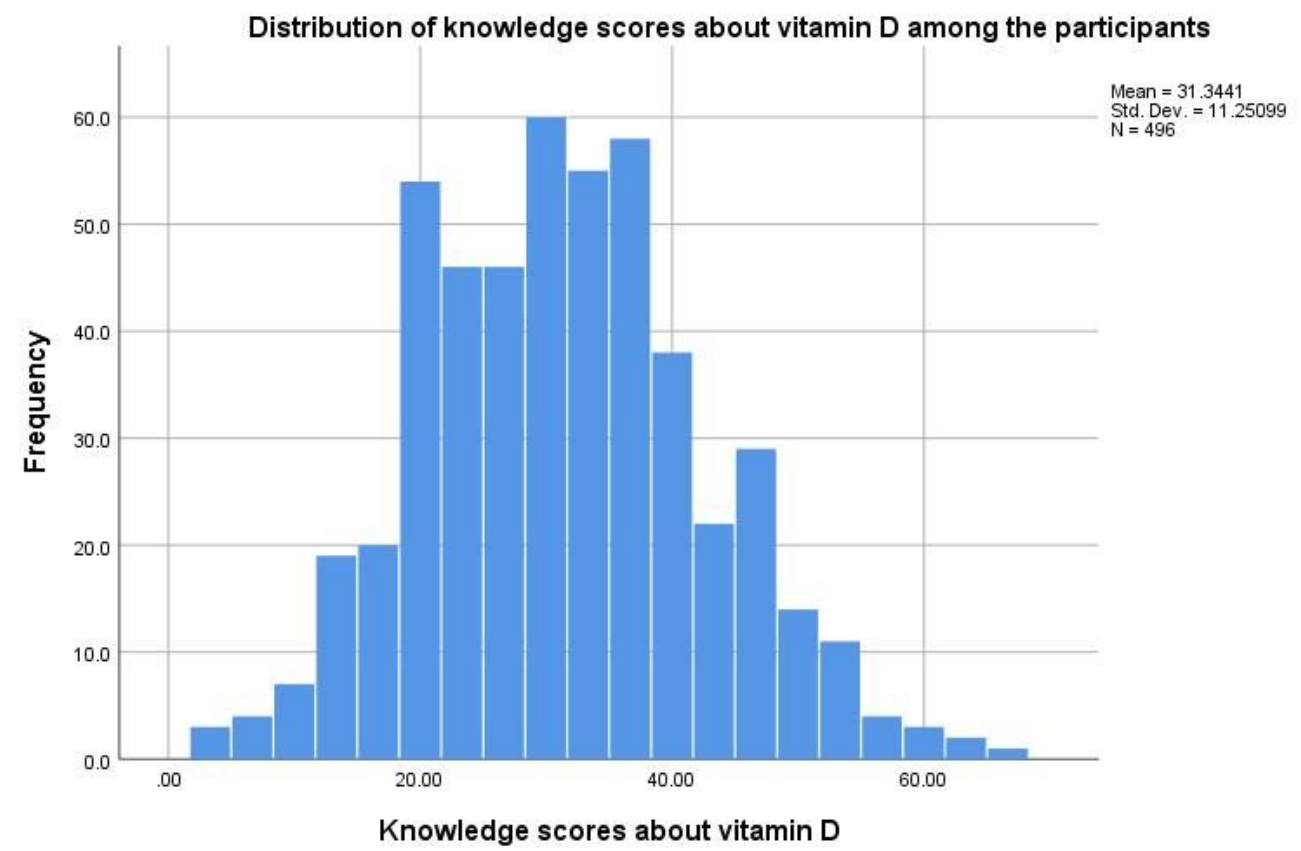

Figure 1

Distribution of knowledge scores about vitamin D among the participants 


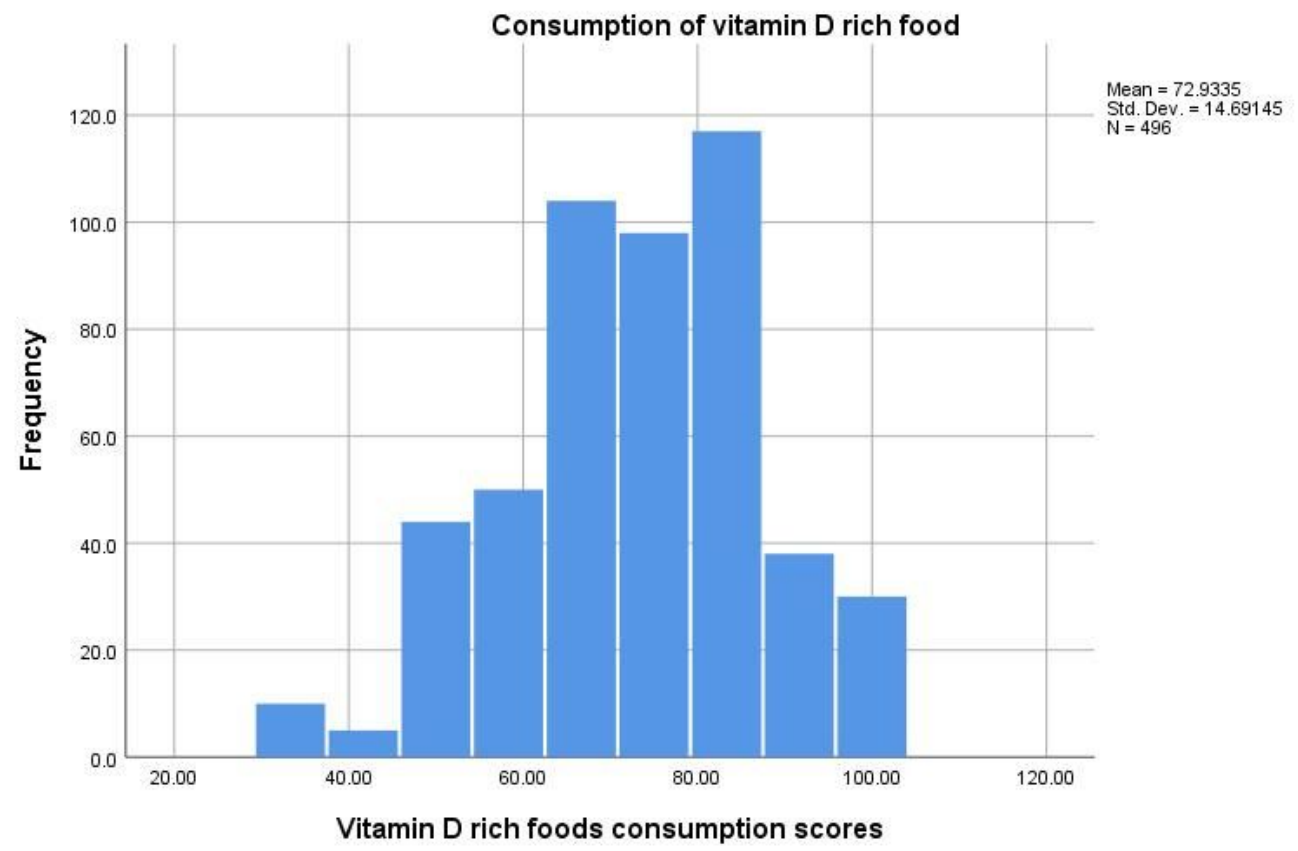

Figure 2

Consumption of vitamin D rich food

\section{Supplementary Files}

This is a list of supplementary files associated with this preprint. Click to download.

- Additionalfile1.docx 